\title{
Prevalence of iron deficiency anemia in Asian female population and human development index (HDI): an ecological study
}

\author{
Elham Goodarzi, MSc ${ }^{1}$, Reza Beiranvand, MSc ${ }^{2}$, Hasan Naemi, MSc ${ }^{3}$, Isan Darvishi, $\mathrm{MSc}^{4}$, Zaher Khazaei, MSc ${ }^{5}$ \\ ${ }^{1}$ Social Determinants of Health Research Center, Lorestan University of Medical Sciences, Khorramabad; ${ }^{2}$ Student Research Committee, Dezful \\ University of Medical Sciences, Dezful; ${ }^{3}$ Iranian Research Center on Healthy Aging, Sabzevar University of Medical Sciences, Sabzevar; ${ }^{4}$ Department \\ of Operating Room, School of Nursing and Midwifery, Shahrekord University of Medical Science, Shahrekord; ${ }^{5}$ Department of Epidemiology, School of \\ Public Health, Ilam University of Medical Sciences, Ilam, Iran
}

\section{Objective}

Anemia is a major problem in developing countries, the purpose of the present study was to investigate the relationship between the human development index (HDI) and the prevalence of anemia among Asian women.

Methods

This was a descriptive-analytic ecological study. The study analyzed data including HDI and prevalence of anemia extracted from the World Bank. The correlation coefficient and analysis of variance were used for data analysis. The significance level was considered to be less than 0.05 . Analyses were performed using Stata-14 software.

\section{Results}

The results revealed that the prevalence of anemia in women of reproductive age $(R=-0.626, P<0.001)$, pregnant women $(R=-0.576, P<0.001)$ and non-pregnant women $(R=-0.623, P<0.0001)$ was significantly negatively correlated with HDI index. In the analysis of HDI components and the prevalence of anemia, a significant negative correlation was observed between the prevalence of anemia and the mean years of schooling, life expectancy at birth, and expected years of schooling indices in all 3 groups of women (non-pregnant, pregnant, and of reproductive age) $(P<0.05)$.

\section{Conclusion}

Since there was a negative correlation between the prevalence of anemia in women and HDI, paying greater attention to factors which influence anemia may contribute to the prevention of anemia in developing countries.

Keywords: Prevalence; Anemia; Asia

\section{Introduction}

Anemia represents a global problem that affects people from all walks of life in all societies. Around a quarter of the world's population suffers from this disease. The problem is not constrained to the medical sector, and its roots can be traced to education, demography, and nutrition. Iron deficiency accounts for about half of the world's anemia. Anemia has caused 19.7 million years of life adapted with disability. The average annual economic loss incurred as a result of iron deficiency anemia in 10 developing countries is estimated at approximately $\$ 16.78$ per capita or $4 \%$ of gross domestic
Received: 2019.10.08. Revised: 2020.02.09. Accepted: 2020.02.10. Corresponding author: Zaher Khazaei, MSc

Department of Epidemiology, School of Public Health, Ilam University of Medical Sciences, Ilam 7419654459, Iran

E-mail: Zaherkhazaei@yahoo.com

https://orcid.org/0000-0001-8619-3664

Articles published in Obstet Gynecol Sci are open-access, distributed under the terms of the Creative Commons Attribution Non-Commercial License (http://creativecommons. org/licenses/by-nc/3.0/) which permits unrestricted non-commercial use, distribution, and reproduction in any medium, provided the original work is properly cited.

Copyright $\odot 2020$ Korean Society of Obstetrics and Gynecology 


\title{
Obstetrics \& Gynecology Science
}

\author{
Vol. 63, No. 4, 2020
}

product (GDP) [1].

Although adults only need $1 \mathrm{mg}$ of absorbable iron daily, iron deficiency anemia remains a widespread issue. Women of reproductive age who have poor diets and suffer from malnutrition are at a greater risk for anemia $[2,3]$. The prevalence of iron deficiency anemia in women is higher than that of men. Despite the economic-scientific advances in recent years, anemia is still prevalent especially in pregnant women and children before school age [4].

The World Health Organization (WHO) estimates that iron deficiency anemia took the lives of 273,000 people in 2004. Of this figure, 45\% were Southeast Asian, 31\% African, 9\% Eastern Mediterranean, 4\% Oceania, and 3\% European. Of all anemia cases, $97 \%$ are found in middle-income countries [5]. Anemia is particularly prevalent in women of reproductive age and children under the age of 5 . Studies in developed countries such as Japan, Sweden, and the United States indicate the rising incidence of iron deficiency anemia in affluent societies. It has also posed a major problem in developing countries such as India over the last 50 years [6].

The results of a study in 185 countries from 1990 to 2011 exhibited that anemia was the most prevalent in Southeast Asia. Extreme cases of iron deficiency anemia can escalate to maternal mortality and preterm labor $[3,7]$. Several factors contribute to the widespread prevalence of micronutrient deficiencies in South Asia including iron deficiency in the diet, poor health, genetic causes, chronic infections, malaria and schistosomiasis $[8,9]$. The prevalence of anemia varies widely in different parts of the world and it is more salient in lower socioeconomic classes [10].

Moreover, as far as the relationship between anemia and the human development index (HDI) is concerned, in areas with a high $\mathrm{HDI}$, anemia-related problems are less noticeable. $\mathrm{HDI}$ represents the essence of human development measures. This index measures the average success of a country in 3 main dimensions of human development, i.e. a long and healthy life, education and appropriate living standards [11].

Given the prevalence of anemia in Asian countries, it is necessary to raise awareness about its contributing factors in order to plan and manage the financial and human resources required to curb its incidence. It is essential for countries to introduce the necessary interventions by comparing their data with those of other countries with regard to the effect of socioeconomic status on the root causes of anemia [11].

The purpose of this study was to explore the impact of so- cioeconomic development (based on $\mathrm{HDI}$ ) on the prevalence of anemia among Asian women based on data retrieved from the World Bank in 2018.

\section{Materials and methods}

The present research was a descriptive-analytic ecological study that investigated the relationship between anemia prevalence in 3 groups of women and its connection with $\mathrm{HDI}$ in Asian countries. The study data included HDI and the prevalence of anemia obtained from the World Bank [12].

\section{Definition of anemia}

Percentage of women aged 15-49 years with a hemoglobin concentration less than $120 \mathrm{~g} / \mathrm{L}$ for non-pregnant women and lactating women and less than $110 \mathrm{~g} / \mathrm{L}$ for pregnant women, adjusted for altitude and smoking $[13,14]$.

\section{Human development index}

The HDI provided by the World Bank delivers the latest data on global development, which includes national, regional and global estimates. According to the Human Development Report, countries are divided into 4 groups: very high human development, high human development, medium human development, and low human development based on the level of the HDI. The numerical value of the HDI is between 0 and 1. It measures efforts taken by each country to reach the highest possible HDI value, and also allows comparisons between countries. HDI represents the essence of human development measures. It measures the mean success of a country in 3 main dimensions of human development: a long and healthy life, access to education and proper living standards [15].

\section{Statistical analysis}

In this study, data analysis was performed using correlation coefficients and an analysis of variance (ANOVA) to investigate the relationship between the prevalence of anemia and $\mathrm{HDI}$. A P-value of less than 0.05 was considered significant. Analyses were performed using the Stata-14 software (StataCorp, College Station, TX, USA). 


\section{Obstetrics \& Gynecology Science}

Elham Goodarzi, et al. Relationship anemia and HDI

\section{Results}

According to the results reported in 2016, the global prevalence of anemia is $32.5 \%$ in non-pregnant women, $40.1 \%$ in pregnant women, and $32.8 \%$ in women of reproductive age. The highest prevalence of anemia in all 3 groups of women (non-pregnant, pregnant, and of reproductive age) was observed in South-East Asia and the lowest in America (Table 1). The analysis of trends in anemia prevalence in 3 groups of women between 2000 and 2016 demonstrates that the prevalence of anemia in all 3 groups was the highest in the South-East Asia region, which was above the global average during these years (Fig. 1).

According to the analysis of the prevalence of anemia, the highest prevalence of anemia in non-pregnant women was recorded in Yemen (70.2\%), Pakistan (52.2\%), and India (51.5\%); the highest prevalence of anemia in pregnant women was recorded in Yemen (63\%), Cambodia (55.8\%), and Myanmar (53.8\%); and the highest prevalence of anemia in women of reproductive age was recorded in Yemen (69.6\%), Pakistan (52.1\%), and India (51.4\%) (Table 2).

The results revealed a significant negative correlation between the prevalence of anemia in women of reproductive age $(R=-0.626, P<0.001)$, pregnant women $(R=-0.576$, $P<0.001)$ and non-pregnant women $(R=-0.623, P<0.001)$ and HDI index (Fig. 2).

In the analysis of $\mathrm{HDI}$ components and the prevalence of anemia in 3 groups of women, a significant negative correlation was observed between the prevalence of anemia in non-pregnant women and mean years of schooling (MYS) $(r=-0.564, P<0.001)$, life expectancy at birth (LEB) $(r=-0.552$, $P<0.001)$, and expected years of schooling (EYS) ( $r=-0.564$, $P<0.001)$. There was a significant negative correlation between anemia prevalence in pregnant women and MYS $(r=-0.563, P<0.001), \operatorname{LEB}(r=-0.439, P<0.001)$, and EYS $(r=-0.534, P<0.01)$. Moreover, there was also a significant negative correlation between the prevalence of anemia in women of reproductive age and MYS $(r=-0.567, P<0.001)$, LEB $(r=-0.553, P<0.001)$, and EYS $(r=-0.566, P<0.01)$. No significant correlation was observed between the prevalence of anemia and GDP in all 3 groups of women ( $P>0.05$ ) (Table 3).

The results of the ANOVA suggested that in non-pregnant women, the highest mean prevalence $(48.7 \pm 19.1)$ belonged to low human development and the lowest mean prevalence $(27.4 \pm 9.2)$ to very high human development, and this differ-

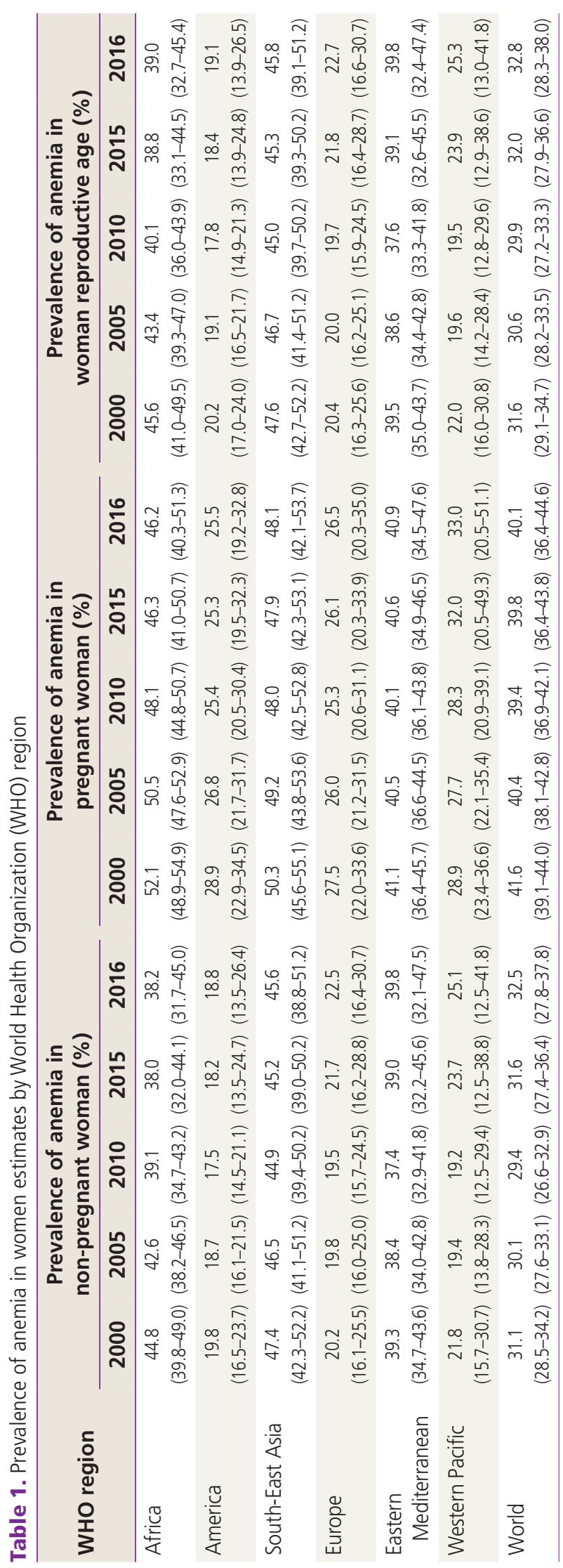




\section{Obstetrics \& Gynecology Science}

Vol. 63, No. 4, 2020

ence was statistically significant ( $F=4.73, P<0.001)$. In pregnant women, the highest mean $(45.7 \pm 8.6)$ belonged to low human development and the lowest mean $(33.8 \pm 6.6)$ to very high human development, and the difference was statistically significant ( $F=4.11, P<0.001)$. These results were comparable to those found in women of reproductive age, with the highest mean prevalence of anemia $(48.8 \pm 18.8)$ belonging to low human development and the lowest mean prevalence to the very high human development (27.6 \pm 9.1$)$. Here, the difference was also statistically significant ( $F=4.73, P<0.001)$ (Table 4).

\section{Discussion}

Iron deficiency anemia has been reported in $25 \%$ of mothers with malnutrition [3]. Pregnant women and young children are more likely to develop anemia. Geographically, people living in Asia and Africa are at a greater risk of anemia. According to the $\mathrm{WHO}$, the prevalence of anemia in all women, pregnant women, and non-pregnant women was 37\%, $51 \%$, and $35 \%$, respectively, in 1988 [16]. The results of this research suggested that, in general, the highest prevalence

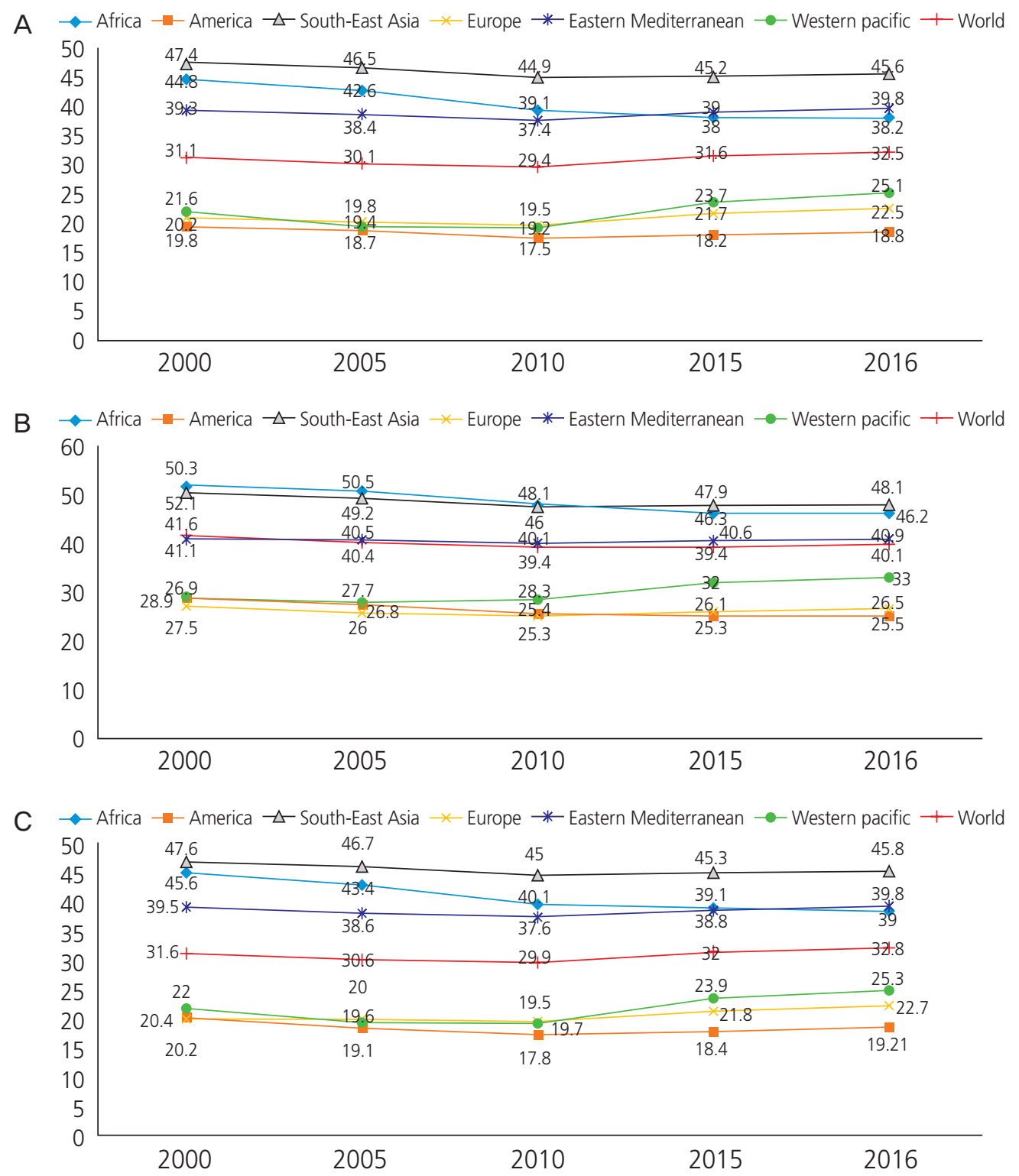

Fig. 1. Trend of anemia prevalence in 3 groups of women. (A) Non-pregnant woman, (B) pregnant woman, (C) woman reproductive age by region World Health Organization. 


\section{Obstetrics \& Gynecology Science}

Elham Goodarzi, et al. Relationship anemia and HDI

Table 2. Prevalence of anemia in Asian women (estimates by country in 2016)

\begin{tabular}{|c|c|c|c|}
\hline Country & $\begin{array}{c}\text { Prevalence of anemia in } \\
\text { non-pregnant woman (\%) }\end{array}$ & $\begin{array}{l}\text { Prevalence of anemia in } \\
\text { pregnant woman (\%) }\end{array}$ & $\begin{array}{c}\text { Prevalence of anemia in } \\
\text { woman reproductive age (\%) }\end{array}$ \\
\hline Afghanistan & $42.4(27.7-55.8)$ & $38.2(24.7-53.3)$ & $42.0(28.2-54.9)$ \\
\hline Armenia & $29.2(12.2-56.3)$ & 35.5 (17.5-63.3) & $29.4(12.6-56.3)$ \\
\hline Azerbaijan & $38.4(25.3-51.8)$ & $40.1(26.9-54.7)$ & $38.5(25.7-51.6)$ \\
\hline Bahrain & $41.9(19.0-67.2)$ & $42.8(20.2-64.8)$ & $42.0(19.7-66.7)$ \\
\hline Bangladesh & $39.6(21.1-55.5)$ & $45.7(28.9-60.1)$ & $39.9(22.0-55.5)$ \\
\hline Bhutan & $35.7(24.8-47.8)$ & $32.8(21.3-47.9)$ & $35.6(25.0-47.3)$ \\
\hline Cambodia & $46.3(36.3-54.2)$ & $55.8(46.0-63.3)$ & $46.8(37.2-54.6)$ \\
\hline China & $26.2(9.8-47.7)$ & $32.4(15.6-57.8)$ & $26.4(10.2-47.5)$ \\
\hline Cyprus & $25.1(9.6-50.6)$ & $29.0(15.2-57.0)$ & $25.2(9.9-50.2)$ \\
\hline Georgia & $27.4(12.9-45.5)$ & $30.1(17.5-50.3)$ & $27.5(13.2-45.3)$ \\
\hline India & $51.5(41.5-58.7)$ & $50.1(42.0-57.2)$ & $51.4(41.8-58.5)$ \\
\hline Indonesia & $28.2(18.7-38.8)$ & $42.0(30.4-53.7)$ & $28.8(19.4-39.0)$ \\
\hline Iran & $30.3(12.7-52.8)$ & $34.1(17.5-57.6)$ & $30.5(13.2-52.4)$ \\
\hline Iraq & $28.7(17.2-44.3)$ & $33.5(19.3-51.6)$ & $29.1(18.0-44.1)$ \\
\hline Israel & $15.2(7.0-38.0)$ & $23.8(12.7-49.9)$ & $15.7(7.5-37.3)$ \\
\hline Japan & $21.2(14.4-31.0)$ & $34.1(18.2-57.6)$ & $21.5(14.8-31.0)$ \\
\hline Jordan & $34.5(20.8-50.0)$ & $37.1(22.9-51.6)$ & $34.7(21.4-49.7)$ \\
\hline Kazakhstan & $30.7(13.0-52.2)$ & $30.4(15.7-54.3)$ & $30.7(13.4-51.2)$ \\
\hline Kuwait & $23.5(9.8-46.3)$ & $31.2(14.8-57.3)$ & $23.8(10.2-46.2)$ \\
\hline Kyrgyzstan & $35.9(21.3-51.5)$ & $39.8(25.1-55.6)$ & $36.2(22.0-51.0)$ \\
\hline Lao People's Democratic Republic & $39.3(19.5-60.7)$ & $45.7(23.8-65.0)$ & $39.7(20.7-60.7)$ \\
\hline Lebanon & $31.1(13.2-55.0)$ & $35.2(17.8-60.1)$ & $31.2(13.6-54.8)$ \\
\hline Malaysia & $24.4(9.4-49.8)$ & $37.1(15.8-63.0)$ & $24.9(10.0-49.7)$ \\
\hline Maldives & $42.4(21.2-60.9)$ & $46.9(18.6-67.5)$ & $42.6(21.9-61.0)$ \\
\hline Mongolia & $18.9(7.1-38.8)$ & $30.3(18.2-49.5)$ & $19.5(8.0-38.4)$ \\
\hline Myanmar & $46.0(34.2-54.7)$ & $53.8(41.5-62.4)$ & $46.3(35.0-54.9)$ \\
\hline Nepal & $34.9(19.2-50.9)$ & $40.0(22.9-57.7)$ & $35.1(19.9-50.9)$ \\
\hline Oman & $38.0(17.4-62.2)$ & $41.8(20.8-62.5)$ & $38.2(18.1-62.1)$ \\
\hline Pakistan & $52.2(35.3-67.4)$ & $51.3(36.4-62.8)$ & $52.1(35.7-67.0)$ \\
\hline Philippines & $14.9(9.7-25.6)$ & $30.3(19.2-45.2)$ & $15.7(10.5-26.1)$ \\
\hline Qatar & $27.5(10.2-52.8)$ & $33.4(15.2-58.5)$ & $27.7(10.6-52.9)$ \\
\hline Saudi Arabia & $42.8(18.0-70.9)$ & $45.5(20.7-65.6)$ & $42.9(18.8-70.5)$ \\
\hline Singapore & $22.0(8.5-50.3)$ & $31.8(15.2-59.6)$ & $22.2(8.7-50.3)$ \\
\hline Sri Lanka & $32.5(14.1-51.3)$ & $35.4(19.2-55.6)$ & $32.6(14.7-51.1)$ \\
\hline Syrian Arab Republic & $33.5(13.8-56.5)$ & $36.1(17.2-60.2)$ & $33.6(14.6-56.3)$ \\
\hline Tajikistan & $30.3(14.0-49.3)$ & $33.5(17.3-57.4)$ & $30.5(14.9-48.5)$ \\
\hline Thailand & $31.6(11.2-70.2)$ & $40.2(15.9-67.6)$ & $31.8(11.7-70.2)$ \\
\hline Timor-Leste & $41.2(25.0-55.9)$ & $42.6(24.5-60.7)$ & $41.3(26.2-55.9)$ \\
\hline Turkey & $30.7(12.0-56.7)$ & $34.4(16.5-60.2)$ & $30.9(12.5-56.6)$ \\
\hline Turkmenistan & $32.6(13.3-54.9)$ & $33.1(16.7-58.1)$ & $32.6(13.8-54.4)$ \\
\hline United Arab Emirates & $27.6(10.8-52.7)$ & $33.2(15.7-59.6)$ & $27.8(11.1-52.6)$ \\
\hline Uzbekistan & $36.8(16.2-52.6)$ & $24.9(14.6-48.5)$ & $36.2(16.6-51.6)$ \\
\hline Viet Nam & $23.7(10.4-43.7)$ & $37.3(19.3-58.5)$ & $24.2(11.0-43.8)$ \\
\hline Yemen & $70.2(54.7-79.7)$ & $63.0(56.3-66.7)$ & $69.6(55.0-78.5)$ \\
\hline
\end{tabular}




\section{Obstetrics \& Gynecology Science}

Vol. 63, No. 4, 2020

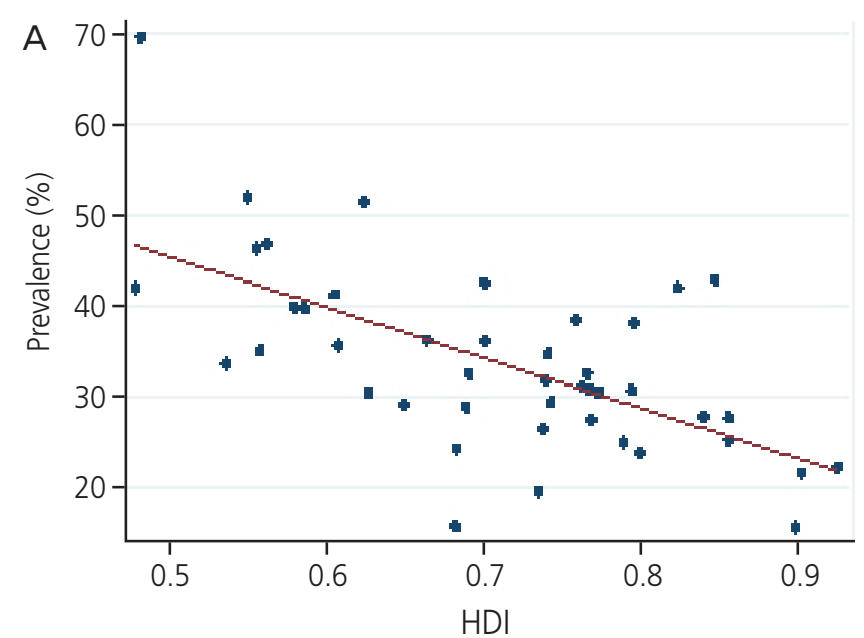

- Prevalence — Fitted values

R Sq. linear $=-0.626, P<0.0001$

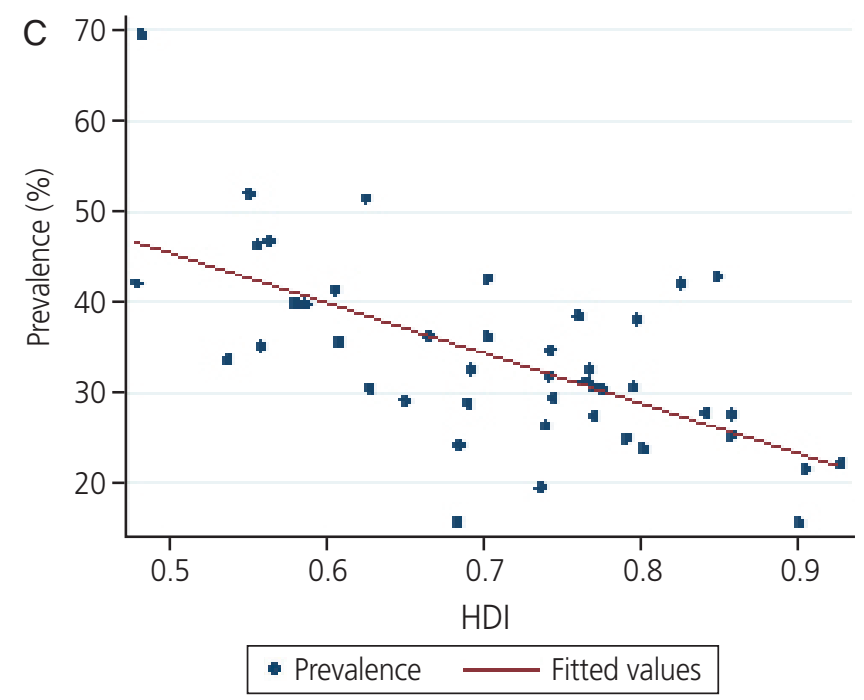

R Sq. linear $=-0.623, P<0.0001$

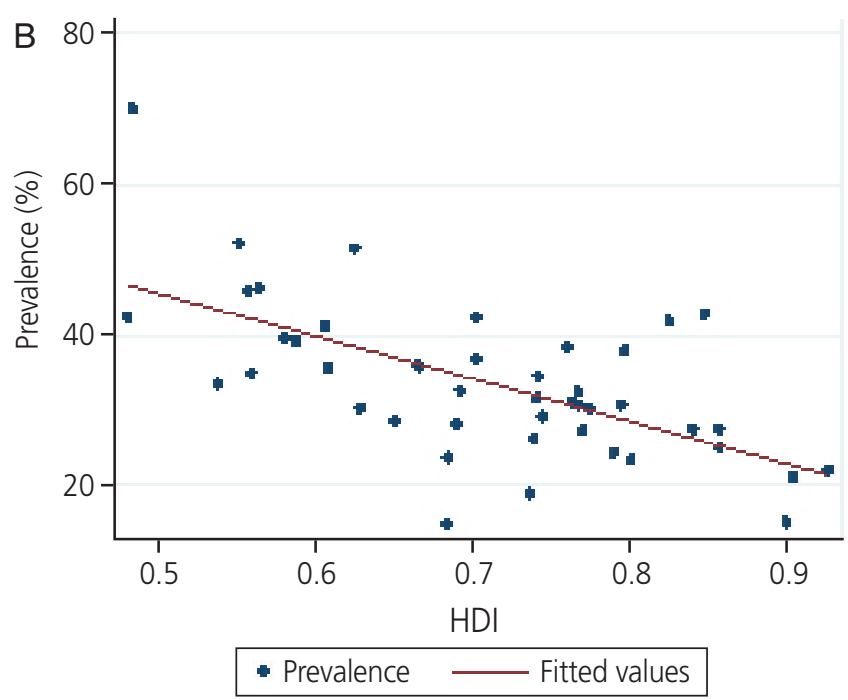

R Sq. linear $=-0.576, P<0.0001$

Fig. 2. Correlation ${ }^{a)}$ between the human development index (HDI) and prevalence of anemia in Asian women. (A) Women reproductive age, (B) pregnant woman, (C) non-pregnant woman in $2016 .{ }^{\text {a) }}$ Statistical method used: correlation coefficient.

Table 3. Pearson correlation between human development index (HDI) component and prevalence of anemia in Asian women in 2016

\begin{tabular}{|c|c|c|c|c|c|c|}
\hline \multirow[t]{2}{*}{ HDI component } & \multicolumn{2}{|c|}{$\begin{array}{l}\text { Prevalence of anemia in } \\
\text { non-pregnant woman } \\
(\%)\end{array}$} & \multicolumn{2}{|c|}{$\begin{array}{l}\text { Prevalence of anemia in } \\
\text { pregnant woman (\%) }\end{array}$} & \multicolumn{2}{|c|}{$\begin{array}{c}\text { Prevalence of anemia } \\
\text { in woman reproductive } \\
\text { age }(\%)\end{array}$} \\
\hline & $r^{a)}$ & $P$-value & $r^{a)}$ & $P$-value & $r^{a)}$ & $P$-value \\
\hline Gross national income per 1,000 capita & -0.284 & $>0.05$ & -0.225 & $>0.05$ & -0.286 & $>0.05$ \\
\hline Mean years of schooling & -0.564 & $<0.001$ & -0.563 & $<0.001$ & -0.567 & $<0.001$ \\
\hline Life expectancy at birth & -0.552 & $<0.001$ & -0.439 & $<0.001$ & -0.553 & $<0.001$ \\
\hline Expected years of schooling & -0.564 & $<0.001$ & -0.534 & $<0.001$ & -0.566 & $<0.001$ \\
\hline
\end{tabular}

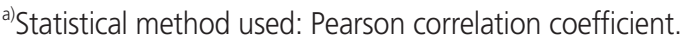




\section{Obstetrics \& Gynecology Science}

Elham Goodarzi, et al. Relationship anemia and HDI

of anemia in non-pregnant women, pregnant woman, and women of reproductive age was observed in Asia, Africa, and Asia, respectively. Moreover, the highest prevalence of anemia in non-pregnant women $(70.2 \%)$, pregnant women $(63 \%)$, and women of reproductive age (69.6\%) was recorded in Yemen.

The lowest incidence of anemia in non-pregnant women was recorded in the Philippines (14.9\%); in pregnant women in Israel (23.8\%); and in women of reproductive age in Japan and the Philippines (15.7\%).

The difference in the prevalence of anemia in these areas can also be attributed to differences in the socioeconomic status of individuals. One indicator that reflects the status of countries is HDI. This index explores the status of a country in 3 key development dimensions, including health, education and living standards. Health is measured with LEB, education with the EYS, and living standards as gross national income per capita or GDP. In countries with high HDI, the prevalence of anemia is lower. The secondary causes of anemia prevalence include timely screening and diagnosis, elevated quality of food, early-stage treatment of malnutrition, and accurate estimation of vitamin intake in these countries [9].

In middle-income countries, the prevalence of anemia is higher; as a result, $97 \%$ of anemia-induced mortality is reported in developing countries [5]. The highest prevalence of anemia in the world is observed in countries with low HDI [17]. In this context, the highest prevalence of anemia has been recorded in Asian countries. Nutritional anemia is widespread not only in developing countries but also in affluent societies $[2,16]$.

The results of a 2016 study by Petry et al. [4] demonstrated that anemia has declined in countries with moderate to high HDI. In this study, iron deficiency anemia in preschool chil- dren and women of reproductive age was $25 \%$ and $37 \%$ in high $\mathrm{HDI}$ communities, respectively, while this figure was higher than the 45\% in low HDI communities. A 2011 study by Oliveira et al. [18] showed that there was an inverse association between the prevalence of anemia and HDI. This study revealed that the prevalence of anemia was significantly higher among blood donors in communities with lower HDI [18]. In their 2012 study, Laxmaiah et al. [19] exhibited that the incidence of $\mathrm{HDI}$ was inversely correlated with the prevalence of anemia. These studies demonstrated that anemia is still a major health issue and the prevention and control of malnutrition should be considered as a key strategy in curbing the prevalence of anemia.

Socioeconomic developments have wielded huge influence on the prevalence of anemia. In low- and middle-income countries, the risk of anemia is increasing. Socioeconomic growth is inversely related to the prevalence of anemia. Chronic infections, nutritional disorders, obesity, chronic noncommunicable diseases, thalassemia, and genetic susceptibility are among the risk factors for anemia. Anemia is linked to HDI in societies, so that according to statistics, the most anemia-related deaths take place in less developed countries [4].

The results of this study demonstrate a significant negative correlation between the prevalence of anemia in non-pregnant women and MYS $(r=-0.564, P<0.001)$, LEB $(r=-0.552$, $P<0.001)$, and $E Y S(r=-0.564, P<0.001) ;$ a significant negative correlation between anemia prevalence in pregnant women and MYS ( $r=-0.563, P<0.001)$, LEB $(r=-0.439$, $P<0.001)$, and EYS $(r=-0.534, P<0.01)$, and a significant negative correlation between the prevalence of anemia in women of reproductive age and MYS $(r=-0.567, P<0.001)$, LEB $(r=-0.553, P<0.001)$, and EYS $(r=-0.566, P<0.01)$. The lower prevalence of anemia in countries with higher HDIs

Table 4. Prevalence of anemia in different human development index (HDI) regions Asian women in 2016

\begin{tabular}{lccc} 
HDI & $\begin{array}{c}\text { Prevalence of anemia in } \\
\text { non-pregnant woman (\%) }\end{array}$ & $\begin{array}{c}\text { Prevalence of anemia in } \\
\text { pregnant woman (\%) }\end{array}$ & $\begin{array}{c}\text { Prevalence of anemia in } \\
\text { woman reproductive age (\%) }\end{array}$ \\
\hline Very high human development & $27.4 \pm 9.2$ & $33.8 \pm 6.6$ & $27.6 \pm 9.1$ \\
High human development & $31.4 \pm 5.8$ & $35.3 \pm 5.3$ & $31.6 \pm 5.6$ \\
Medium human development & $36.3 \pm 10$ & $41.7 \pm 8.1$ & $36.5 \pm 9.8$ \\
Low human development & $48.7 \pm 19.1$ & $45.7 \pm 8.6$ & $48.8 \pm 18.8$ \\
$P$-value (F-test) & $<0.001$ & $<0.001$ & $<0.001$ \\
\hline
\end{tabular}

Data are shown as mean \pm standard deviation.

a) Statistical method used: analysis of variance. 


\section{Obstetrics \& Gynecology Science}

Vol. 63, No. 4, 2020

could be attributed to factors such as the existence of micronutrients in foods, more accurate diagnostic methods and enhanced access to primary health care.

The major factors contributing to the high prevalence of anemia in most countries are low income levels and malnutrition. Hence, one effective step to mitigate the prevalence of anemia is to provide primary anemia prevention strategies such as increasing household per capita and providing food packages for families. Despite the interrelation of these factors, caution should be practiced when interpreting such studies because, in addition to the environmental factors of anemia prevalence, the limitations of descriptive studies should also be taken into consideration. Early prevention and epidemiological studies, especially for people in less developed countries, can help reduce the burden of disease and improve health status in these countries.

In women from different south-east Asian regions iron deficiency anemia should ideally be addressed through dietary diversification and improved access to foods that have high levels of bioavailable iron, including animal products. Daily or intermittent iron supplementation, alone or together with folic acid and other micronutrients, can be used for high-risk groups (children, pregnant women and women of reproductive age), to improve iron intake. These strategies should be tailored to local conditions, taking into account the specific etiology and prevalence of anemia in a given setting and population group, and should be built into the primary health-care system and existing programs.

In conclusion, the results of the present study suggest a negative correlation between the prevalence of anemia in women and HDI. Moreover, the prevalence of anemia in these countries was negatively correlated with LEB and education. Hence, a study of factors that raise the prevalence of anemia in countries with low HDI can go a long way in reducing its incidence rate. Further, raising the level of a mother's education and her awareness can also contribute to a reduced incidence.

\section{Acknowledgements}

This work was supported by Kerman University of Medical Sciences, Kerman, Iran.

\section{Conflict of interest}

No potential conflict of interest relevant to this article was reported.

\section{Ethical approval}

The study was approved by Ethic Committee (IR.KMU. REC.1398.505).

\section{Patient consent}

The patients provided written informed consent for the publication and the use of their images.

\section{References}

1. World Health Organization. Iron deficiency anemia. Assessment, prevention, and control. A guide for programme managers. Geneva: World Health Organization; 2001.

2. Saxena Y, Shrivastava A, Saxena V. Effect of gender on correlation of anaemia with body mass index in medical students. Indian J Physiol Pharmacol 2011;55:364-9.

3. Seshadri S. Prevalence of micronutrient deficiency particularly of iron, zinc and folic acid in pregnant women in South East Asia. Br J Nutr 2001;85 Suppl 2:S87-92.

4. Petry N, Olofin I, Hurrell RF, Boy E, Wirth JP, Moursi M, et al. The proportion of anemia associated with iron deficiency in low, medium, and high human development index countries: a systematic analysis of national surveys. Nutrients 2016;8:693.

5. World Health Organization. Global health risks: mortality and burden of disease attributable to selected major risks. Geneva: World Health Organization; 2009.

6. Hallberg L, Hultén L, Lindstedt G, Lundberg PA, Mark A, Purens J, et al. Prevalence of iron deficiency in Swedish adolescents. Pediatr Res 1993;34:680-7.

7. World Health Organization. The global prevalence of anaemia in 2011. Geneva: World Health Organization; 2015.

8. Roy CN. Anemia of inflammation. Hematology Am Soc 


\section{Obstetrics \& Gynecology Science}

Elham Goodarzi, et al. Relationship anemia and HDI

Hematol Educ Program 2010;2010:276-80.

9. Mockenhaupt FP, Rong B, Günther M, Beck S, Till H, Kohne $E$, et al. Anaemia in pregnant Ghanaian women: importance of malaria, iron deficiency, and haemoglobinopathies. Trans R Soc Trop Med Hyg 2000;94:477-83.

10. Khambalia AZ, Aimone AM, Zlotkin SH. Burden of anemia among indigenous populations. Nutr Rev 2011;69:693-719.

11. Shih YC, Chien CR, Xu Y, Pan IW, Smith GL, Buchholz TA. Economic burden of renal cell carcinoma in the US: part II--an updated analysis. Pharmacoeconomics 2011;29:331-41.

12. Gordon EJ, Leon JB, Sehgal AR, Hoffart N. Why are hemodialysis treatments shortened and skipped? Development of a taxonomy and relationship to patient subgroups. Nephrol Nurs J 2003;30:209-17.

13. World Health Organization. Haemoglobin concentrations for the diagnosis of anaemia and assessment of severity. Geneva: World Health Organization; 2011.

14. World Health Organization. Prevalence of anaemia in pregnant women (\%) [Internet]. Geneva: World Health Organization; c2016 [cited 2019 Jan 17]. Available from: https://www.who.int/data/gho/data/indicators/ indicator-details/GHO/prevalence-of-anaemia-in-pregnant-women-(-)?bookmarkld=56cd5b17-0a02-480e8205-abc912b8e333.

15. Anand S, Sen AK. Human development index: methodology and measurement. New York (NY): United Nations Development Programme; 1994.

16. McLean E, Cogswell M, Egli I, Wojdyla D, de Benoist B. Worldwide prevalence of anaemia, WHO vitamin and mineral nutrition information system, 1993-2005. Public Health Nutr 2009;12:444-54.

17. Barkley JS, Wheeler KS, Pachón H. Anaemia prevalence may be reduced among countries that fortify flour. $\mathrm{Br}$ J Nutr 2015;114:265-73.

18. Oliveira CD, Martins G, Custer B, Proietti FA, CarneiroProietti $A B$, César $C C$. Hierarchical analysis of anaemia deferral in blood donor candidates: the individual in the population perspective. Transfus Med 2011;21:371-7.

19. Laxmaiah A, Arlappa N, Balakrishna N, Mallikarjuna Rao K, Galreddy C, Kumar S, et al. Prevalence and determinants of micronutrient deficiencies among rural children of eight states in India. Ann Nutr Metab 2013;62:231-41. 